\title{
Accelerated reforms in healthcare financing: the need to scale up private sector participation in Nigeria
}

\author{
Ufuoma John Ejughemre*
}

\begin{abstract}
The health sector, a foremost service sector in Nigeria, faces a number of challenges; primarily, the persistent under-funding of the health sector by the Nigerian government as evidence reveals low allocations to the health sector and poor health system performance which are reflected in key health indices of the country. Notwithstanding, there is evidence that the private sector could be a key player in delivering health services and impacting health outcomes, including those related to healthcare financing. This underscores the need to optimize the role of private sector in complementing the government's commitment to financing healthcare delivery and strengthening the health system in Nigeria. There are also concerns about uneven quality and affordability of private-driven health systems, which necessitates reforms aimed at regulation. Accordingly, the argument is that the benefits of leveraging the private sector in complementing the national government in healthcare financing outweigh the challenges, particularly in light of lean public resources and finite donor supports. This article, therefore, highlights the potential for the Nigerian government to scale up healthcare financing by leveraging private resources, innovations and expertise, while working to achieve the universal health coverage.

Keywords: Nigeria, Healthcare Financing, Health System, Private Sector

Copyright: @ 2014 by Kerman University of Medical Sciences

Citation: Ejughemre UJ. Accelerated reforms in healthcare financing: The need to scale up private sector participation in Nigeria. Int J Health Policy Manag 2014; 2: 13-19. doi: 10.15171/ijhpm.2014.04
\end{abstract}

\section{Article History:}

Received: 5 October 2013

Accepted: 1 December 2013

ePublished: 9 December 2013

\section{Correspondence to:}

Ufuoma John Ejughemre

Email: ufuoma.ejughemre@delsuth.com.ng

\section{Introduction}

In many developing countries such as Nigeria, the health sector suffers from the lack of financial and human resources (1). There is a constrait on health sector resources; yet the demand for health services is increasing at an alarming rate in these countries. In Nigeria, the situation has been exacerbated by the strain on these resources posed by health challenges such as infant and maternal health, HIV/AIDS and the problems of non-communicable diseases. It is also worrisome that the country with a population of about 170 million is the most populous country in Africa (2); sadly, its health sector, a foremost service sector is perennially under-funded by the government (estimated to be $5 \%$ of GDP) and have to compete with other important social service sectors such as housing, transportation, environment, and security (3). There are also concerns that the health sector continues to fail in meeting the burgeoning user needs and demands (4). Notably, it is the fact that the challenges facing this sector placed the country at a dismal 187th position out of 191 United Nations member states in health systems performance by the World Health Organization (WHO) in the year 2000 (5). Regrettably, since the year 2000, these unpleasant findings still reflect in key health indices such as Maternal Mortality Ratio (MMR) and Infant Mortality Rates (IMR). Current estimates reveal that MMR as high as 1500 deaths per 100,000 live births $(6,7)$ and IMR as high as 74.36 deaths per 1,000 live births were recorded in the country in 2012, with the IMR placing the country as the 16th worst in IMRs out of 221 countries globally by 2013 (8). While these issues continue to be a lasting challenge in healthcare delivery in Nigeria, the current situation of Nigeria's expenditure reflects a meagre 80 US dollars per capita (9). Although, it could be said that high investment in healthcare does not necessarily translate into "good" health $(10,11)$, the challenge is that hitherto, government budgetary allocation to health in Nigeria has been low. It arises from limited "fiscal space" and "low domestic resource mobilization capacity" which constrain the government from significantly increasing the level of resources allocated to health. Nevertheless, there is evidence that the private sector can be a key player in delivering health services and impacting health outcomes, including those related to healthcare financing (12). This therefore, underscores the need to optimize the role of the private sector in complementing government's commitment to financing healthcare in Nigeria. However, there are concerns about uneven quality and affordability of private-driven health systems, thus necessitating key reforms aimed at scaling up and regulating the private sector in complementing government's efforts in healthcare delivery. This was noted at the 63rd World Health Assembly (WHA) where the resolution on "Strengthening the Capacity of Governments to Constructively Engage the Private Sector in Providing Essential Healthcare Services" was passed (13). The resolution and accompanying 
report acknowledge that private provision of health services will lead to providing better services, financing health goals, and ultimately improving a nation's health status if optimized. This article, therefore, highlights the potential for the Nigerian government to scale up healthcare financing by leveraging private resources, innovations, and expertise while working to achieve the universal health coverage.

\section{Methods for review}

As literature reviews are summaries of research evidence that address research issues by using explicit methods to identify, select, critically appraise relevant research studies, and analyze data from the studies that are included for the review, the author made this study as inclusive as possible.

\section{Search methods}

By using key words, the author involved a broad search of literatures on healthcare financing and health financing policy in Nigeria, health system funding, Public-Private Partnerships (PPPs) in healthcare delivery, Private Health Insurance (PHI), community financing, inter alia. Via broad criteria, online search engines and databases including Pubmed, Medline, and Google Scholar were searched; websites and online resources of international organizations as well as hand searches of bibliographic records were also taken into consideration. However, the author did not contact experts or universities. Original searches were conducted between March and midOctober 2013 and this generated 20 documents that were included for the review.

\section{Selection criteria}

To generate evidence for the review, studies between 2000-2013 were considered and findings included were from literature reviews, expert commentaries, cross-sectional studies, panel discussions as well as grey literatures that reported an objective measure of at least one of the following outcomes: healthcare financing, utilization and coverage, quality of health, health expenditures, and health outcomes in health systems as well as PPPs in health systems in Nigeria and developing countries with health systems closely related to the Nigerian health system.

\section{Data collection and analysis}

The findings generated from all included studies formed the themes to critically analyze health financing reforms needed to strengthen private sector participation in healthcare financing in the country. There was no detailed data synthesis and quality, as the study is not a systematic review.

\section{Summary of Results}

Three main issues emerged from included studies and these were: (i) Poor health expenditure: total and per capita (ii) The constraints to increase government's budgetary allocation to healthcare financing in Nigeria (iii), and Health financing policy: strengthening the private sector participation. All included studies suggested the need to scale up private sector participation in healthcare financing in Nigeria (Table 1).

\section{Overview of healthcare financing in Nigeria}

The situation in Nigeria shows that government funding for the health sector has been unsatisfactory over the years. Evidence reveals that by the early 1980s the annual government allocation to health was estimated at 533.6 million US dollars
$(14,15)$. It follows that this was sustained with policy prospects of increasing budgetary allocations to healthcare; however, it nose-dived, reaching a trough of 58.8 million US dollars in 1987 (15,16). Nevertheless, between 1996 and 1999, there was a significant increase in national health expenditure, and by 2002 it rose to 524.4 million US dollars (17), then climaxing to about 1.79 billion US dollars in 2013 (18). While there may have been increases in allocation to health, the irregularity in budgetary allocation to health reflects in the percentage of total annual government budget, as evidence reveals a pattern from as low as $3.6 \%$ in 1996 increasing to $5.0 \%$ in 1997 ; then declining to a paltry $2.7 \%$ in 2000 and then rising marginally to $5.6 \%$ by 2013 (16-18). In fact, this irregularity connotes the lack of proper planning in the health system and health service projections which takes little cognizance of rising healthcare cost amidst dwindling services per capita. Overall, the percentage of health budget which falls at about 5\% of GDP is a far cry from the WHO's recommendation of $15 \%$ of the total national budget for African countries (17-19). Some other reports even reveal that it remained at about $1 \%$ in the 1990 s to just under $5 \%$ in the last decade $(20,21)$.

Furthermore, microeconomic analysis shows that the per capita expenditure on healthcare in Nigeria is a meagre 80 US dollars (22). While there have been marginal increments by 13 US dollars from 2010 to 2013 (22), on the contrary, some other countries in the Sub-Saharan African region, such as South Africa and Angola, spend seven and three times more per capita on healthcare respectively than Nigeria does (22). More so, the per capita expenditure on healthcare in Nigeria actually pales into insignificance when compared with some developed countries like the United States which spends an average of 7,000 US dollars per capita; Switzerland, which spends about 6,000 US dollars per capita; or an average of 3,600 US dollars per capita among developing countries in Europe (22). Nevertheless, high investment in health does not necessarily translate into "good" health, typical of such is with the United States which spends $17.4 \%$ of its GDP on health, whereas the UK spends 9.8\%, Norway 9.6\%, and Japan 8.5\%; the United States health status is "poor" when compared with OECD countries $(23,24)$. Reasons include: rising number of the uninsured (24), decreasing access to health services due to high prices for drugs, procedures, office visits amongst other things in the United States (24). However, unlike the United States and other OECD countries, the critical issue is that expenditure on health in Nigeria is insignificant when compared with OECD countries.

Interestingly, the private sector of the health system continues to grow in Nigeria and there is evidence that it plays a crucial and significant role in healthcare financing in the country (25). For instance, of Total Health Expenditure (THE) in the country between 1999-2002, Private Health Expenditure (PvtHE) accounted for between 65.5-78.2\%, while government expenditure, in the same period, ranged between $21.8-33.5 \%$ of THE (25). The situation barely changed by 2010 with PvtHE accounting for $62 \%$ of the THE (26). Further analysis showed that private households' out-of-pocket payments accounted for 90-94\% of private payments, while prepaid and risk pooling constituted only $2.4-6.7 \%$ with minimal changes by 2012 (26). But, recent policy reforms in health financing in Nigeria may have sought to improve reallocation of public expenditure in line with identified priorities, strengthening appropriate pricing policy in health services and increased attention to health 
Table 1. Summary of included studies

\begin{tabular}{|c|c|c|c|c|}
\hline Study/Author(s) & Study design & Year of study & Settings & Summary \\
\hline $\begin{array}{l}\text { Health Reform Foundation in } \\
\text { Nigeria, } 2007\end{array}$ & Health review & 1996-2007 & Nigeria & THE remained $<5 \%$ by 2005 \\
\hline Appropriation Bill, 2013 & Policy briefs & 2012-2013 & Nigeria & $\begin{array}{l}\text { Marginal increase in appropriation to } \\
\text { health at } 5.6 \%\end{array}$ \\
\hline World Bank, 2000 & World Bank reports & 1990-1998 & Nigeria & $\begin{array}{l}\text { Expenditure on Health as a percentage } \\
\text { (\%) of GDP; at }<1 \%\end{array}$ \\
\hline $\begin{array}{l}\text { Nigeria Health Expenditure, } \\
2013\end{array}$ & Panel discussion reports & 1995-2010 & Nigeria & PvtHE remained at $62 \%$ of THE \\
\hline Novignon et al. 2012 & Panel data analysis & 1995-2010 & Sub-Saharan Africa & $\begin{array}{l}\text { Increased health indices following } \\
\text { increased private and public health } \\
\text { system financing }\end{array}$ \\
\hline SURE-P, 2013 & $\begin{array}{l}\text { Panel discussion on } \\
\text { government funding }\end{array}$ & 2013 & Nigeria & $\begin{array}{l}\text { Increased primary and secondary } \\
\text { facility care }\end{array}$ \\
\hline World Bank, 2013 & Review of GDP growth rates & 2004-2012 & Nigeria & $\begin{array}{l}\text { Increased economic prospects with a } \\
\text { GDP rate of } 6.6 \%\end{array}$ \\
\hline Central Bank of Nigeria, 2005 & $\begin{array}{l}\text { Annual reports and } \\
\text { statement of accounts }\end{array}$ & 2001-2003 & Nigeria & $\begin{array}{l}\text { Accelerated growth in government } \\
\text { funding of health system }\end{array}$ \\
\hline Uzochukwu BSC, 2012 & $\begin{array}{l}\text { Panel discussions: a review of } \\
\text { the Nigerian situation }\end{array}$ & 2012 & Nigeria & $\begin{array}{l}\text { Policy reforms to strengthen the } \\
\text { private involvement }\end{array}$ \\
\hline La Forgia and Harding, 2009 & $\begin{array}{l}\text { A review of PPPs in São } \\
\text { Paulo, Brazil }\end{array}$ & 2009 & Brazil & $\begin{array}{l}\text { Efficiency in health system } \\
\text { performance }\end{array}$ \\
\hline Vicente and Castillejo, 2012 & $\begin{array}{l}\text { A review of the Brazilian } \\
\text { experience in modernizing } \\
\text { hospitals }\end{array}$ & 2011-2012 & Brazil & $\begin{array}{l}\text { Efficiency in health system } \\
\text { performance }\end{array}$ \\
\hline Purohit BC, 2005 & Cross-sectional study & 2005 & India & $\begin{array}{l}\text { Efficiency in health system } \\
\text { performance }\end{array}$ \\
\hline La Forgia et al. 2005 & Case study & 2005 & Guatemala & $\begin{array}{l}\text { Efficiency in primary health system } \\
\text { performance }\end{array}$ \\
\hline Rao et al. 2011 & Supplement article & 2009-2010 & Ethiopia & $\begin{array}{l}\text { Decreased incidence of HIV and other } \\
\text { related diseases }\end{array}$ \\
\hline Meessen et al. 2011 & Review article on PBF & $2005-2008$ & Rwanda & $\begin{array}{l}\text { Efficiency in health system } \\
\text { performance }\end{array}$ \\
\hline Obansa SA, 2013 & $\begin{array}{l}\text { Review paper of health } \\
\text { financing }\end{array}$ & 1998-2007 & Nigeria & Proposes health financing reforms \\
\hline Adinma and Adinnma, 2010 & Review paper & - & Nigeria & Strengthening CBHF \\
\hline Carrin et al. 2005 & Data review & 1997-2001 & Developing countries & Strengthening $\mathrm{CBHF}$ \\
\hline McIntyre et al. 2010 & Systematic review & - & Developing countries & Strengthening CBHF \\
\hline ILO/STEP & Policy briefs & - & Developing countries & $\begin{array}{l}\text { Strengthening micro insurance } \\
\text { schemes through research }\end{array}$ \\
\hline
\end{tabular}

SURE-P= Subsidy Reinvestment and Empowerment program, CBHF= Community-Based Health Financing, PBF= Performance-Based Financing, ILO/STEP= International Labour Organization/Skills Training and Employment Placement

insurance (27,28). Funding of healthcare delivery through the SURE-P is now channelled toward the common causes of morbidity in Nigeria which are still preventable infectious and avoidable diseases (28). However, it is important to consider that the challenges of financing the health system still largely rest on the shoulders of the government.

Public financing of health system: the analysis of the constraints Given the background of the poor national budgetary allocation to financing of healthcare delivery in Nigeria, health policy analysts may be tempted to ask "what is the capacity of the Nigerian government to increase the allocation to the health sector, and what factors constrain or enhance this capacity?" There are a number of macro-economic or fiscal space factors which are associated with the capacity for increased government financing of health. They include: economic growth and tax revenues, borrowing, grants, etc (29). Although, these may be theoretically available to the government, the importance of macro-economic stability and fiscal sustainability effectively limit pursuing these options realistically in the country.

\section{Economic growth and tax revenues}

While considerations may be made to increase budgetary allocation to health in Nigeria, it may be worthwhile to consider recent economic trends in the country as a pedestal to leverage upon. Succeeding reports noted that throughout the years 2004 to 2012, growth rates in Nigeria were appreciating marginal (30). Given this, it is interesting to also note that there are optimistic reports regarding growth prospects in the country in the course of this new decade (31). For instance, facts show that the average annual percentage change in GDP (at constant prices) for Nigeria between 2004-2012 was at 6.6\% (31). Such growth provides the potential for further resources to be made available for financing health priorities and improving outcomes. Notably, steady economic growth patterns encourage foreign direct investment, which can contribute to the creation of fiscal space indirectly, thereby generating tax revenue for health. Nevertheless, while these prospects appear to continue 
in the country, increased budgetary allocation to health service delivery through increased taxation rates remains at a level of rhetoric in Nigeria, for the following reasons: (i) tax administration systems are weak and inefficient (ii) a substantial informal sector of many small businesses and enterprises that are 'invisible' to tax authorities narrows the tax base, making it difficult to raise tax rates without first broadening the tax base (iii) high rates of tax evasion by businesses or individuals in the private sector exists (iv) higher tax rates are politically unacceptable, especially in the context of the very low incomes for the majority of the population, and (v) increased taxes arguably have the potential to distort incentives in the economy and to impact negatively on the private sector (31). It then implies that widening government budgetary allocation to health becomes a 'mirage' as raising taxes in the country remains a herculean task.

\section{Borrowing and grants}

Occasionally, experts will posit that borrowing to invest in current health priorities can increase the country's human capital and productivity, and, thereby, enhance its ability to repay a loan collected. However, there is the need for the government to carefully consider whether the terms of return on a given type of health expenditure justifies the cost of borrowing. The country only just got international pardon on its huge debtdeficit and there are reports of accumulating debt profiles by all tiers of government (32). The import is that, there is not enough room for additional borrowing to finance healthcare delivery. Furthermore, while international developmental assistance may also come to bear as a way of funding health systems in the country and increase the capacity for the government to increase its spending on healthcare delivery; however, there is the potential that large inflows of international developmental aids may actually foster disincentives for the Nigerian government to increase its domestic resource mobilization as the sector becomes over reliant on donor support. It follows that, donor support is only a part of the development picture. Economic growth and social progress as well as sustainable and workable policies for gradually exiting from donor funding for health is needful, as over dependence on humanitarian actors will continue to cripple the country's ability to be self-sufficient and self-reliant in financing its health system.

Health financing policy: strengthening the private sector involvement

As there is the need for policies to scale up private sector participation in Nigeria, it follows that the health financing policy in Nigeria: (i) mandates government at all levels in the country to allocate at least $15 \%$ of its total budgets to health in line with the Abuja Declaration (ii) provides a framework for establishing social health insurance and Community-Based Health Insurance (CBHI) schemes within the context of the National Health Insurance Scheme (NHIS), so as to expand cover to the informal and rural populations which make up $70 \%$ of the population, as a strategy toward the universal access (iii) supports for voluntary (private) health insurance and discouragement of retainership (iv) identifies, adapts and scales up financing schemes shown to expedite the universal coverage, such as drug revolving fund schemes, etc (v) harmonizes external aids and partnerships for health financing (vi) promotes domestic philanthropy, and (vii) discourages out-of-pocket health expenditure (32). But a reflection on recent reforms in health financing in Nigeria reveals that the government has strengthened the health system through improved allocation of funding in line with identified priorities amongst others (33). But then, it has been stipulated in the Nigerian National Health Policy (NNHP) that "the government of the federation shall explore avenues for financing the healthcare system" (34). These avenues include: PPPs, PHI, Community-Based Financing (CBF) amongst others. Notwithstanding, 'private' involvement in critical areas like health insurance, PPPs in health services, and community health financing are still embryonic in the country, but evidence from countries such as Brazil (35), India (36) and a number of Sub-Saharan African countries (1) reveals that increased private sector participation in financing the health system will be a "magic bullet" to ease the burden on the government and help address the monumental burden of healthcare delivery.

\section{Public-Private Partnership}

Reforms through PPPs are critical to note. Chiefly is the fact that within the health sector, PPPs (where private finance and/or provision supersedes that of the public) will address failing internal managerial reforms by increasing funding to the health sector and improves management efficiency and innovation in healthcare services, while it also accelerates the modernization of the health system (35). Going by this, PPPs as a measure to address the burgeoning challenges in health system financing in the country will come to bear if a number of issues are critically reflected upon with a view to implementation. Of such will include: autonomous authority and strategic purchasing in health services.

\section{Autonomous authority}

In most developing countries including Nigeria, the national health service remains the backbone of the health system (37). The dominant mode of governance in these countries is centralisation where the central government and the ministry of health perform nearly all functions of the health system including resource collection, pooling of funds, purchasing, regulation, provision, employment, drug supply, ownership of infrastructure and equipment, and monitoring and evaluation. In fact, it is a truism that decisions related to these including those related to healthcare financing are usually centralized. Despite this, there are facts that reveal PPPs will provide a strong measure to address the challenges facing health systems in this regard $(38,39)$. However, it is possible that PPPs in healthcare delivery may be difficult to be implemented in Nigeria. Interestingly, evidence from developing economies such as Guatemala and Brazil reveals that these can be achieved anywhere, as they are cost-effective and provide increased efficiency in managing health resources $(38,39)$. This will come to bear if: (i) contracts/agreements in setting up these systems provide autonomous authority to PPPs where managers of health systems are given the decision-making authority to run their facilities (ii) there is the freedom to manage budgets as needed to meet the set performance targets (iii), and it reduces the political interference $(38,39)$.

\section{Strategic purchasing}

Strategic purchasing through the principle of PBF strengthens the need for scaling up PPPs in Nigeria. Scientific facts have shown that $\mathrm{PBF}$ arrangements provide organizational units rights over their resources (40). This implies that organizational 
units will not have to rely on hierarchical relationships but on contractual or regulatory ones. For instance, in health facilities, a fee-for-service look-alike model combined with scoring based on a quality checklist, such as having one or more fully immunized child that produces an additional unit of service, can be rewarded (40). Besides, these arrangements can also go a long way to encourage the health facility to set up a bonus contract with staff as a reward. The key example is from Rwanda which reveals that such an approach is used and it takes into cognisance the individual contribution through working days, responsibilities and qualification (41). Experience from other parts of the Sub-Saharan African region suggests that with this sort of arrangement, the central government will keep decision rights regarding key public health priorities, firmly exercising this right through its purchasing power and at the same time, ready to transfer decision rights focused on the delivery of priority health interventions to health facilities in existing PPPs (40). Additionally, these will amongst others; provide greater accountability and improved efficiency (allocative and technical efficiency) in the health system, as one of the main challenges facing the health system in Nigeria is the waste of scarce resources. It will give stronger incentives to satisfy users as facilities can then tailor their initiatives to the populations they serve. With this in mind, health facilities can, for instance, pressurize their suppliers to receive the inputs required to make their provision of services attractive, thus addressing the problem of allocative inefficiency (40).

Nevertheless, one could be tempted to think that PPPs systems are 'magic bullets' by themselves. Rather, evidence reveals that weak monitoring has been the 'Achilles heel' of PPPs in developing countries (39). This may explain why past PPPs programmes in Nigeria have failed. However, avoiding such will necessitate reviewing and analyzing hospital data and negotiating budgets with health facility managers where PPPs are functioning with regular audits conducted by the state or independent bodies to review contract compliance periodically. More so, establishing robust processes of standardized costaccounting systems in PPPs service centres will enhance transparency in such programs. Facts also from Brazil, where there is the use of cost as a basis of budget negotiations, is a critical example for Nigeria (39). Ultimately, as part of internal managerial reforms in health systems, these arrangements insures that healthcare providers pay more attention to health information systems and, as such, they properly and completely fill in information forms as a "must", as data provided constitutes part of the basis for their remuneration (40). This will in no doubt help to curb the chronic issue of absenteeism in health services. In spite of these, it could be said that the National Health Policy (NHP), which was revised in 2004 and approved by the Federal Government and National Council on Health in Nigeria, already provided a favorable platform to generate a reliable information base system for informed decision-making and performance assessment (34), but taking a cue from PPPs could help in speedily resolving the current challenges of poor health information systems and data management as it will function to strengthen the Nigerian health system.

\section{Private Health Insurance}

Disturbed by the paucity of funds to finance healthcare delivery, the national health insurance scheme was established by the government of Nigeria in 1985 (42). Although this was proposed to significantly improve health financing and access to healthcare by Nigerians, unfortunately this has not been the situation as the design of the health insurance policy is a typical "Top-Down" approach rather than "Bottom-Up". This is because it has so far focused on individuals in the public sector of employment which constitutes an insignificant proportion of the Nigerian populace, promoting in-equity in access to health services indirectly. This, therefore, necessitates scaling up alternatives in line with the national health policy, through PHI schemes.

The PHI schemes are still rudimentary in developing countries including Nigeria; however, where they do exist, and where regulation is light, they are moderately successful, garnering a small but not negligible market share (usually among the upper and middle class) and making modest profits $(43,44)$. In Nigeria, a negligible fraction of about $0.7 \%$ of the population is enrollees in private insurance schemes, and this calls for its expansion across the country (43). Nevertheless, while PHIs may come to bear; for-profiting, moral hazard and adverse selection will be a huge setback to resource mobilization, risk pooling and guaranteeing of access to health services in a country where there is the monumental problem of health inequality. Notwithstanding, to combat the problem of moral hazard, cost sharing or co-payments, measures have been put in place by many organizations providing PHI (43). Furthermore, as these financing arrangements are implemented by Health Maintenance Organizations (HMOs) for a fixed periodic per capita payment or by Preferred Provider Organizations (PPOs), there is the need for regulation of HMOs and PPOs. This calls for reforms in setting up HMOs (at national, regional and state levels) such as tighter fiscal regulations for capital base in these organizations as well as emphasizing more on robust programs by providers of PHIs in order to address the basic principles of solidarity, the rising issues of adverse selections, moral hazards, actuarial ratings, solvency requirements, cross-subsidization, and control of exclusion which are now of concern in the insurance market (44). Tackling these will see the scaling up of PHIs and health financing reforms in the country. This is because decreases in direct payments, will increase the utilization of health services $(45,46)$, quality of care $(47)$, the universal coverage (47) and cost recovery ratios for health systems $(46,47)$ as well as sustainability in healthcare financing.

\section{Community-Based Financing}

Addressing the health financing gap in the country through increased private sector participation will also require strengthening CBF. This is because, $\mathrm{CBF}$ is now seen as a viable and sustainable pre-payment scheme for sub-urban and rural communities (48). However, locally developed CBF schemes focusing on the very poor and self-employed populations remain relatively rare (49). But within the last 15-20 years, there have been experiments in $\mathrm{CBF}$ catering for these populations in developing countries (50). These have received increasing attention from policy makers in the recent past and they are now recognized as community initiatives that are both community friendly and have a wider reach than other health insurance or pre-payment schemes in the informal sector, especially if well-designed (50). The reason is that they are essentially a household co-financing system which are more viable options in rural settings when compared with other health insurance schemes which have problems of inefficiency in premium collections, bureaucratic obstacles, tedious claiming processes, and poor coverage. This necessitates the need for more 
political commitment and public advocacy to garner support if substantial results will be achieved through these schemes as many Nigerians live in the rural communities and are engaged in the informal sector. More so, international developmental assistance will also come to bear. This will require more support in financing such schemes as well as research in community health financing. The ILO/STEP program is one of such schemes, which are to bear the reform process of the country (51). Equally, regular evaluation and surveillance of these schemes will be critical if sustainability is anything to go by in Nigeria.

\section{Discussion and policy lesson}

The benefits of engaging the private sector to expand the financing of health systems cannot be underestimated. Accordingly, the growing recognition of the importance of strong health systems provides an unprecedented prospect to steadily include the private sector as an integral part of Nigeria's health system strengthening strategy. Although, there have been efforts geared at increasing public funding to health in Nigeria, statutory allocation to health will not address the burgeoning health needs for about 170 million people. What the available evidence reveals is that, the Nigerian government's budgetary allocation to health has been low (about $5 \%$ of GDP) and it is a far cry from the WHO's recommendation of $15 \%$ for African countries $(18,19)$. This arises from the challenge of limited fiscal space and low domestic resource mobilization capacity (29). The poor funding of healthcare delivery reflects in the per capita expenditure on healthcare in Nigeria (placed at 80 US dollars) (9), and the problem of health inequality and the high burden of diseases in the face of rising costs for healthcare services.

Against this backdrop, it is necessary for the private sector to be systematically engaged by the government as there are facts already suggesting an increase in the private sector's role to meet the rising demand for healthcare in Nigeria and other developing countries $(52,53)$. Although, there are concerns about the quality and standardization with private involvement, interestingly, private financers of healthcare will follow national guidelines and adhere to standards when regulated. If private sector is unregulated, however, the growth of private involvement in health system financing and strengthening health system could worsen inequities, limit health outcomes and undermine efforts to improve national health coverage as well as jeopardizing the economic well-being of health clients. This necessitates striking a balance between the government as a regulator and the private sector as a co-financier. Accordingly, there is the urgent need for reforms that will establish PPPs in healthcare delivery, scaling up health insurance, and community health financing schemes amongst others. For instance, in countries like Brazil and Guatemala, PPPs have been instituted as reforms to strengthen health financing $(35,36)$. Additionally, financing arrangements such as PBF in public health facilities should be considered as a financing reform in the national health policy. This is because it will strengthen the health system in the country through improving leadership and effectiveness, increase absorptive capacity and strengthen the health workforce, thereby help existing and additional resources go further at all levels of care $(38,39)$. Typical of such models is seen in low-resource countries in the Sub-Saharan African region such as Rwanda and Burundi where their governments have set up PBF at national levels with significant results in health system performance $(40,41)$. Furthermore, while it is hoped that the SURE-P may be worthwhile to increase absorptive capacity and strengthen the weak health system, it has challenges of sustainability. Besides, much more needs to be done in scaling up health insurance. It is hoped that CBF and $\mathrm{PHI}$ will adequately narrow the gaps in the national social health insurance if well-implemented. More so, as user fees continue to be a source of controversy, what is needful is that user-fee policy should be linked to the broader package of financing (such as health insurance coverage) and with a view on averting any form of equity danger that will thus arise. Accepting this implies that efforts made to achieve equity, efficiency, and in particular, sustainability require implementing a wider policy package that will include the development of skills, systems and mechanisms needed to insure effective implementation thereof. This will then strengthen the need to accelerate the private sector's contribution to health financing in the country.

Ultimately, providing enabling policies, regulatory environment and creating appropriate incentives for more private involvement in complementing government's responsibility, is of paramount importance for achieving health targets in an equitable manner. It will be impossible to achieve the universal health coverage at the current level of investment in health in Nigeria as the only option is for the government to constructively engage the private sector to support its efforts in financing the health system.

\section{Acknowledgements}

I give all gratitude to God Almighty for his inspiration and the suggestions of the anonymous reviewers.

\section{Ethical issues}

Not applicable.

\section{Competing interests}

The author declares that he has no competing interests. The views and opinions expressed in this article are those of the author and do not reflect the official policy or position of any governmental agency.

\section{Author's contribution}

UJE is the single author of the manuscript.

\section{References}

1. American Public Health Association. Strengthening health systems in developing countries [internet]. 2008. [cited 2013 Oct 19]. Available from: http://www.apha.org/advocacy/policy/policysearch/ default.htm?id=1375

2. Central Intelligence Agency (CIA). World Facts Book [internet]. 2013. [cited 2013 Sep 16]. Available from: https://www.cia.gov/ library/publications/the-world-factbook/fields/2119.html

3. Adetokunbo L. Primary Health Care in Nigeria, Health Reform Foundation in Nigeria (HEFRON). Nigerian Health Review, 2007. p. 24.

4. Das Gupta M, Gauri V, Khemani S. Primary Health Care Service Delivery in Nigeria. Survey Evidence from Lagos and Kogi. Development Research Group. Washington, DC: World Bank; 2003.

5. World Health Organization (WHO). World Health Report 2000. Health Systems, Improving health performance. Geneva: WHO; 2000.

6. Adegoke AA, Campbell M, Ogundeji MO, Lawoyin TO, Thomson AM. Community Study of maternal mortality in South West Nigeria: how applicable is the sisterhood method. Matern Child Health J 2013; 17: 319-29.

7. Guerrier G, Oluyide B, Keramarou M, Grais R. High maternal and neonatal mortality rates in northern Nigeria: an 8-month observational study. Int $J$ Womens Health 2013; 5: 495-9. 
8. CIA Facts Book [internet]. 2012. [cited 2013 Oct 8]. Available from: http://www.indexmundi.com/g/r.aspx?v=29

9. World Bank. Health expenditure per capita [internet]. 2013. [cited 2013 Oct 10]. Available From: http://data.worldbank.org/indicator/ SH.XPD.PCAP

10. Schoen C, Doty MM, Robertson RH, Collins SR. Affordable Care Act Reforms Could Reduce the Number of Underinsured U.S. Adults by 70 Percent. Health Affairs 2011; 30: 1762-71.

11. Anderson GF, Markovich P. Multinational Comparisons of Health Systems Data, 2010. New York: The Commonwealth Fund; 2011.

12. IFC. The Business of Health in Africa: Partnering with the Private Sector to Improve People's Lives. Washington, DC: International Finance Corporation; 2007.

13. World Health Organization (WHO). Strengthening the Capacity of Governments to Constructively Engage the Private Sector in Providing Essential Health-Care Services [internet]. 2010. Available from: http://apps.who.int/gb/ebwha/pdf_files/WHA63/A63_25-en. pdf

14. Health Reform Foundation in Nigeria (HERFON) [internet]. Available from:http://www.herfon.org/home.html

15. Consultative Group of Nigeria. Nigeria, economic strategy and policy: The Way Forward. Federal Government of Nigeria Abuja, 2000.

16. Central Bank of Nigeria (CBN). Annual Report and Statement of account, 2000.

17. Health Reform Foundation in Nigeria (HERFON). Nigeria Health Review. 2006. [cited 2013 Oct 8] . Available from: http://www.herfon. org/home.html

18. Appropriation Bill [internet]. 2013. [cited 2013 Oct 8]. Available from: http://www.nassnig.org/nass2/legislation.php?id=1583

19. World Health Organization (WHO). Africa Public Health Alliance \& 15\%+ Campaign [internet]. 2010. [cited 2012 May 19]. Available from: http://www.who.int/workforcealliance/members_partners/ member_list/aphra/en/index.html

20. Central Bank of Nigeria (CBN). Annual Reports and Statement of Accounts. World Bank Country Report for Nigeria, 2005.

21. World Bank. African Development Indicators. Washington, DC: World Bank; 2000.

22. World Bank Health Expenditure per capita [internet]. [cited 2013 Sep 16]. Available from: http://data.worldbank.org/indicator/SH.XPD. PCAP

23. Trading economic index [internet]. 2013. [cited 2013 Aug 17]. Available from: http://www.tradingeconomics.com/nigeria/gdp

24. David A, Squires DA. Explaining High Health Care Spending in the United States: An International Comparison of Supply, Utilization, Prices, and Quality. New York: The Commonwealth Fund; 2011.

25. Soyibo A, Coordinator P. National Health Accounts of Nigeria, 1998-2002. Geneva: World Health Organization; 2005.

26. Nigeria Health Expenditure. Total versus Private [internet]. 2013. [cited 2013 Oct 11]. Available from: http://nigeria.opendataforafrica. org/msqivrf/nigeria-health-expenditure-total-vs-private

27. Obansa SAJ. Health Care Financing in Nigeria: Prospects and Challenges. Mediterranean Journal of Social Sciences 2013; 4: 231.

28. Adinma ED, Adinnma BJ. Community based healthcare financing: An untapped option to a more effective healthcare funding in Nigeria. Niger Med 2010; 50: 95-9.

29. Heller P. Back to Basics -- Fiscal Space: What it is and how to get it. Finance and Development 2005; 42(2). Available from: http:// www.imf.org/external/pubs/ft/fandd/2005/06/basics.htm

30. Trading economic index [internet]. [cited 2013 Aug 17]. Available from: http://www.tradingeconomics.com/nigeria/gdp

31. African Union. Fourth Session of The African Union Conference Of Ministers of Health Addis Ababa, Ethiopia, 2009. p. 16-7.

32. The Vanguard. Nigerian economy on a debt cliff [internet]. 2013. [cited 2013 Sep 17]. Available from: http://www.vanguardngr. com/2013/06/nigerian-economy-on-a-debt-cliff/

33. The Post. SURE-P Targets More Investment in Health Sector [internet]. 2013. [cited 2013 Oct 10]. Available from: http://thepost- ng.com/sure-p-targets-more-investment-in-health-sector/\#. UleA7VBwocc

34. Uzochukwu BSC. Health Care Financing, A review of the Nigerian Situation. Health Reform Foundation Scientific Meeting, 2012. p. 5-10.

35. Vicente R, Castillejo J. The role of Public Private Partnership. The Brazilian experience in modernizing hospitals in Sao Paoulo Prefecture Health Secretariat. World Hosp Health Serv 2012; 48: 20-3.

36. Purohit BC. Private initiatives and policy options: recent health system experience in India. Health Policy Plan 2001; 16:87-97.

37. Bryan L, Conway M, Keesmat T, McKeena S, Richardson B. A practical guide to Health System Strengthening in sub-Saharan Africa. Health International 2009; 1-3. Available from: http:// www.africa.com/mckinsey-on-africa/strengthening_sub-saharan africa8217s_health_systems_a_practical_approach

38. La Forgia G, Mintz P, Cerezo C. Is the Perfect the Enemy of the Good: A Case Study on Large Scale Contracting for Basic Health Services in Rural Guatemala. In: Gerard M. La Forgia, editors. Health Systems Innovations in Central America: Lessons and Impacts from New Approaches. Washington, DC: World Bank; 2005.

39. La Forgia GM, Harding A. Public-private partnerships and public hospital performance in São Paulo, Brazil. Health Aff (Millwood) 2009; 28: 1114-26.

40. Meessen B, Soucat A, Sekabaraga C. Performance-based financing: just a donor fad or a catalyst towards comprehensive health-care reform? Bull World Health Organ 2011; 89: 153-6.

41. Meessen B, Musango L, Kashala JP, Lemlin J. Reviewing institutions of rural health centres: the Performance Initiative in Butare, Rwanda. Trop Med Int Health 2006; 11: 1303-17.

42. Federal Ministry of Health. Report of the special committee on national health care financing. Lagos: Federal Ministry of Health:1985.

43. Ogunbekun I, Ogunbekun A, Orobaton N. Private health care in Nigeria, walking a tightrope. Health Policy Plan 1999; 14: 174-81.

44. Wonderling D, Gruen R, Black N. Introduction to Health Economics. $5^{\text {th }}$ Edition. Maidenhead : Open University Press; 2010.

45. Schoen C, Osborn R, Squires D, Doty MM, Pierson R, Applebaum S. How health insurance design affects access to care and costs, by income, in eleven countries. Health Aff (Millwood) 2010; 29: 2323-34.

46. Weisbrod BA. The health care quadrilemma: an essay on technological change, insurance, quality of care, and cost containment. J Econ Lit 1991; 29: 523-52.

47. Keehan SP, Cuckler GA, Sisko AM, Madison AJ, Smith SD, Lizonitz JM, et al. National Health Expenditure Projections: Modest Annual Growth Until Coverage Expands And Economic Growth Accelerates. Health Affairs 2012; 31: 1600-12.

48. World Health Organization (WHO). Report of the Commission on Macroeconomics and Health. Geneva: WHO; 2001.

49. Criel B, Kegels G. A health insurance scheme for hospital care in Bwamanda District, Zaire: lessons and questions after 10 years of functioning. Trop Med Int Health 1997; 2: 654-72.

50. Carrin G, Waelkens MP, Criel B. Community-based health insurance in developing countries: a study of its contribution to the performance of health financing systems. Trop Med Int Health 2005; 10: 799-81.

51. International Labour Organization, ILO/STEP. Methodological guide for undertaking case studies: health micro insurance schemes. Geneva: ILO; 2000.

52. Rao P, Gabre-Kidan T, Mubangizi DB, Sulzbach S. Leveraging the private health sector to enhance HIV service delivery in lowerincome countries. J Acquir Immune Defic Syndr 2011; 57: S116-9.

53. Novignon J, Olakojo SA, Nonvignon J. The effects of public and private health care expenditure on health status in sub-Saharan Africa: new evidence from panel data analysis. Health Econ Rev 2012; 2 : 22. 